Running title: Physical Activity and ADHD

\title{
PHYSICAL ACTIVITY AND ADHD: EVIDENCE ON DEVELOPMENTAL TRAJECTORIES, TRANSIENT AND DURABLE NEUROCOGNITIVE EFFECTS, AND REAL-WORLD APPLICATIONS
}

\author{
ACTIVIDAD FÍSICA Y TDAH: EVIDENCIA EN EL DESARROLLO, EFECTOS \\ NEUROCOGNITIVOS A CORTO Y LARGO PLAZO Y SUS APLICACIONES
}

\author{
(original version in English) \\ Eduardo Esteban Bustamante ${ }^{1}$, María Enid Santiago-Rodriguez ${ }^{1}$, Jared Donald Ramer ${ }^{1}$, \\ Guilherme Moraes Balbim ${ }^{1}$, Tara Gisela Mehta1 ${ }^{1}$, Stacy Lynn Frazier ${ }^{2}$ \\ ${ }^{1}$ University of Illinois at Chicago, ${ }^{2}$ Florida International University \\ Original submission: 2018-09-25. Resubmitted: 2019-04-10. Accepted: 2019-04-23. Published: 2019-06-13.
}

\begin{abstract}
THE PROBLEM: Attention-Deficit/Hyperactivity Disorder (ADHD), the most common childhood mental health disorder in the United States, is the behavioral manifestation of neurodevelopmental delays. Physical activity (PA) is broadly accessible, culturally acceptable, and influences many of the same neurocognitive systems delayed in ADHD. These factors make PA a potential tool in treatment and management plans. This selective qualitative review synthesizes findings from studies investigating PA, fitness, and motor coordination in ADHD. INCLUSION AND EXCLUSION CRITERIA: Studies of PA [and related constructs] in youth on the spectrum for ADHD. MAIN RESULTS: Cross-sectional studies suggest children with ADHD evidence similar or higher PA levels than typically developing peers in childhood-a period when most PA is free play - but any advantages dissipate by adolescence, as PA programs become increasingly structured and selective. In adulthood, individuals with ADHD are more likely to be obese and less likely to meet healthy lifestyle guidelines. Longitudinal studies suggest that PA at earlier life stages predicts symptom severity in subsequent stages. Acute bout experiments suggest transient benefits on neurocognitive function following moderate-intensity activity of limited duration. Multi-week intervention studies have tested diverse formats with results that differ based upon the chosen outcome and comparison group utilized. CONCLUSION AND PRACTICAL APPLICATIONS: Existing research suggests youth with ADHD may benefit most from PA interventions that challenge cognition and fundamental movement skills in childhood, empower youth to participate in structured programs and meet PA guidelines in adolescence, and strategically time PA bouts to maximize focus during difficult periods of daily routines.
\end{abstract}

Keywords: exercise, physical fitness, motor coordination, mental health, child development

\section{RESUMEN}

PROBLEMA: El trastorno por Déficit de Atención e Hiperactividad (TDAH) es caracterizado por retrasos en el desarrollo neurobiológico. La actividad física (AF) puede influir en varios de los mecanismos neurocognitivos que también son afectados por el TDAH, por lo tanto, puede considerarse parte del tratamiento y manejo del TDAH. Esta revisión sobre TDAH resumirá estudios que evaluaron AF, aptitud física y coordinación motora. CRITERIOS DE INCLUSIÓN/EXCLUSIÓN: Fueron incluidos artículos sobre AF en la niñez en el espectro de TDAH. RESULTADOS: Estudios transversales: niños con TDAH presentan niveles de AF más 
altos que los niños aparentemente saludables. La niñez coincide con oportunidades para participar en juego libre, pero esta ventaja es reducida durante la adolescencia en la cual la AF es estructurada y menos inclusiva. Durante la adultez, personas con TDAH están más propensos a ser obesos y a no adoptar las recomendaciones de estilos de vida saludables. Estudios longitudinales: AF durante etapas tempranas predice la severidad de los síntomas del TDAH en etapas subsecuentes. Otros estudios: AF moderada de corta duración brinda beneficios neurocognitivos. Resultados sobre intervenciones de varias semanas difieren según la variable de interés y el grupo con el cual es comparado la intervención. CONCLUSIÓN/IMPLICACIONES: Intervenciones de AF que retan las habilidades cognitivas y destrezas de movimientos brindan beneficios a los niños con TDAH. Además, estimulan a los niños y adolescentes a participar en AF estructurada, cumplir con la recomendación de AF y a incluir AF de corta duración como parte de las rutinas diarias.

Palabras Claves: ejercicio, aptitud física, coordinación motora, salud mental, desarrollo en la niñez

\section{Colloquial Summary:}

Some children have severe difficulties paying attention, controlling themselves, and sitting still. These are symptoms of Attention-Deficit/Hyperactivity Disorder (ADHD). Conventional treatments for ADHD are therapy and medication. Findings from a modest number of crosssectional, longitudinal, short bout, and multi-week intervention studies show benefits of physical activity for brain function, thinking, and behavior of children with ADHD. Physical activities that are engaging and cognitively challenging may benefit children's cognition most. Short bouts of moderate-intensity aerobic physical activity improve energy, focus, and performance on puzzlelike tasks, but we do not know much about how they affect children's classroom behavior in the real-world. Unfortunately, children with ADHD are more likely to be sedentary and obese as adults, potentially because they are less likely to develop adequate fundamental movement skills or participate in structured physical activities (for example, sports) than typically developing children, and are more likely to exceed recreational screen time guidelines. 
Running title: Physical Activity and ADHD

\section{INTRODUCTION}

Attention Deficit Hyperactivity Disorder (ADHD) is the most common childhood mental health disorder in the United States, affecting an estimated 5.1-million children, 9\% of American youth (Visser, Deubler, Bitsko, Holbrook, \& Danielson, 2016). Across Latin America, prevalence rates are similar with estimates ranging from 5-6\% in Brazil (Arruda, Querido, Bigal, \& Polanczyk, 2015) and Puerto Rico (Bird et al., 2006) to 10\% in Chile (Vicente et al., 2012) and Venezuela (Montiel, Peña, Montiel-Barbero, \& Polanczyk, 2008). ADHD is characterized by a persistent pattern of inattention and/or hyperactivity/impulsivity that interferes with daily functioning and development. The precise etiology of ADHD is unknown and the heterogeneity of neurobiological deficits (e.g., smaller brain sizes, volume asymmetries, and delayed cortical development) suggest multiple potential pathways to impairment (Halperin, Berwid, \& O’Neill, 2014).

Evidence from neuroimaging, genetic epidemiology, and medication studies suggest that neurotransmitters may play an important role in the disorder. Neurotransmitters are chemical messengers created in nerve cells (i.e., neurons) that carry information across spaces (i.e., synapses) where neighboring neurons receive them through appropriate receptors. Most of the human neural reward system relies on the neurotransmitter dopamine to communicate between neurons, dopamine is secreted in the presence of potentially rewarding stimuli and is positively related to both motivation and reward (Volkow et al., 2009). Cross-sectional studies suggest that ADHD correlates with genetic polymorphisms affecting action of the dopamine transporter (DAT1) in the striatum (Jeong et al., 2015) and dopamine receptor (DRD4) in the prefrontal cortex (Swanson et al., 1998). In both cases, associated polymorphisms result in reduced neurotransmitter concentrations (Diamond, 2007). Clinical trials reveal that children with ADHD benefit from treatment with methylphenidate or amphetamine (Jensen et al., 2001). The former acts to inhibit dopamine transporter (DAT) (Volkow, Wang, Fowler, \& Ding, 2005), which is responsible for removing dopamine and norepinephrine from the synapse, while the latter increases release of dopamine and norepinephrine (Diamond, 2007). Imaging studies provide further evidence of neurotransmitter dysregulation, as investigators have found that children with ADHD evidence fewer dopamine synaptic markers (Volkow et al., 2009), hypo-arousal at rest (Barry, Clarke, Johnstone, McCarthy, \& Selikowitz, 2009), and hypo-activation in networks involved with executive function (EF) and attention (Cortese et al., 2012) compared to typically developing (TD) peers. EF is a broad construct encompassing cognitive functions necessary for reasoning, problem solving, planning, organization, and behavioral execution (Diamond \& Lee, 2011). A meta-analysis of 6,703 children found that those with ADHD performed significantly worse on neuropsychological tests of EF-puzzle-like tasks—than TD peers even after controlling for relevant covariates (Willcutt, Doyle, Nigg, Faraone, \& Pennington, 2005).

Physical Activity (PA) is a broad term encompassing all bodily movement produced by the skeletal muscles that increase energy expenditure above resting levels (Caspersen, Powell, \& Christenson, 1985). In contrast, exercise is a type of PA undertaken in order to achieve a specific health- or performance-related objective (Caspersen et al., 1985). Consistent participation in PA and exercise results in improved health and strength, termed physical fitness, as well as a host of neurocognitive and psychological benefits (Piercy et al., 2018). Initial interest in research on exercise, PA, and physical fitness in children with ADHD arose from a perceived alignment between some of the neurocognitive deficits associated with ADHD and the neurocognitive benefits that accompany PA in non-ADHD populations (especially EF and increases in circulating neurotransmitter levels) (Halperin et al., 2014). In adults, aerobic PA increases cortical blood flow (Ogoh \& Ainslie, 2009) and neurotransmitter secretion; and it has long been posited that these changes increase arousal and enhance cognitive performance (Davey, 1973). 
Running title: Physical Activity and ADHD

Studies of single bouts of aerobic PA in typically developing (TD) children demonstrate transient increases in circulating neurotransmitters, cognitive speed, and inhibition following exercise bouts, though benefits are not evident in more complex cognitive challenges (e.g., planning, task switching) (Verburgh, Königs, Scherder, \& Oosterlaan, 2014). Therefore, evidence suggests the effects of moderate intensity acute bouts of exercise promote focus, alertness, and taskperformance by shifting an individual's state for transient periods; however, no single bout of PA in isolation would be expected to substantively alter neurodevelopment trajectory or to durably alter intelligence. With regard to durable neurodevelopmental benefits, multi-week exercise intervention studies (3- to 9-months) have demonstrated benefits in neurocognitive function in normal weight (Hillman et al., 2014) and overweight and obese children (Davis et al., 2011). Significant outcomes included alterations in brain function-via electroencephalogram (EEG) (Hillman et al., 2014) and functional magnetic resonance imaging (fMRI) (Davis et al., 2011), white matter integrity via diffusion tensor imaging (DTI) (Schaeffer et al., 2014), neuropsychological tasks of EF (Davis et al., 2011; Hillman et al., 2014), and math performance (Davis et al., 2011).

A fast-growing literature investigates relationships between PA [and related constructs, such as motor coordination, physical fitness, and organized sport participation], and neurocognitive, behavioral, and academic functioning of children with [or on the spectrum for] ADHD. This selective qualitative review provides an overview of the state-of-evidence on: (1) observational studies of PA and ADHD across developmental stages; (2) experiments testing effects of acute bouts of PA for children with ADHD; and (3) experiments and observational studies testing durable effects of long-term exercise participation for children with ADHD.

\section{Observational Studies of PA AND ADHD ACross DeVelopmental StAGeS}

By definition, children with ADHD are more "hyperactive" than TD peers, therefore, one might assume they also have higher levels of coordination, fitness, and PA. However, a counter point to these assumptions is that children with ADHD [not on medication] are $40 \%$ more likely [and ADHD adults $70 \%$ more likely] to be obese than TD peers (Cortese \& Tessari, 2017). Two longitudinal studies demonstrate that $34 \%-41 \%$ of children with ADHD go on to become obese adults-compared to 22\%-25\% among TD peers (Castaneda et al., 2016; Cortese et al., 2013). These seemingly contradictory realities suggest potential differences in healthy lifestyle trajectory across developmental stages. Unfortunately, we are unaware of any longitudinal studies comparing PA behavior in children with ADHD with those of TD peers over the course of development. Nevertheless, a synthesis of cross-sectional studies across developmental stages may inform some preliminary hypotheses for future testing.

\section{STUDIES IN EARLY CHILDHOOD (AGES 4-6)}

To date, two cross-sectional studies have investigated relationships between accelerometermeasured PA and parent/teacher-reported inattention and hyperactivity. First, in a study of 450 unmedicated preschool children, higher scores of hyperactivity/inattention related to lower body fat percentage, and higher levels of PA and sedentary time as measured by accelerometry (Ebenegger et al., 2012). The authors note, however, hyperactivity/inattention were also positively related to excessive television viewing and unhealthy eating habits. The second study provided accelerometers to 247 preschool children, again investigators found that higher levels of accelerometer-measured moderate-vigorous PA (MVPA) were associated with greater externalizing symptoms (McNeill, Howard, Vella, Santos, \& Cliff, 2018). These preliminary findings suggest that the impulsivity and hyperactivity that characterize ADHD provide a benefit in promoting MVPA during a time when PA is dominated by unstructured free play. However, these characteristics may also make children more susceptible to pleasurable, highly stimulating 
Running title: Physical Activity and ADHD

obesogenic activities. Given that children with ADHD participate in more MVPA starting in early childhood, one would expect to see physical fitness advantages as well. However, a comparison of six tests of physical fitness between 18 preschool children in the highest $5 \%$ of ADHD symptoms in their school and 18 same-aged peers in the lowest $5 \%$ of ADHD symptoms in the school revealed that the low-symptom group evidenced better (though not statistically significantly better) performance across fitness tests at baseline (e.g., 50 more sit-ups in 60-seconds, sit-andreach average 60-cm greater) (Golubović, Milutinović, \& Golubović, 2014).

\section{STUDIES IN MIDDLE-LATE CHILDHOOD (AGES 7-12)}

During middle-late childhood, preliminary evidence suggests children with ADHD remain more [or similarly] physically active but other troubling disparities emerge, including decreased performance of fundamental movement skills, lower physical fitness, and less organized sport participation. A small cross-sectional study in Taiwan provided 20 male elementary school students with ADHD and 20 male same-aged peers with accelerometers for 7 days. Investigators found higher levels of accelerometer-measured PA in the ADHD group compared to the TD group (Lin, Yang, \& Su, 2013). An hour-by-hour post-hoc analysis revealed that children with ADHD participated in higher amounts of PA during unstructured periods, despite low levels of PA during structured periods, offering some evidence that children with ADHD are more active at this age due to hyperactivity during free play. Analyses of the National Health and Nutrition Examination Survey (NHANES) data from 2003-2004 provide additional support for these disparities. When comparing 188 children, 6-17 years-old, diagnosed with ADHD to 2,325 TD peers, children diagnosed with ADHD evidenced significantly greater accelerometer-measured MVPA (M=59.9 vs. $M=51.7$ minutes/day) than TD peers, were more likely to meet US PA guidelines of 60 -minutes of MVPA per day (45\% vs. $35 \%)$, and evidenced fewer minutes of accelerometermeasured sedentary time ( $M=416$ minutes vs. $M=435$-minutes). Diagnostic status remained a significant predictor after controlling for race/ethnicity, gender, family income, and age (Ramer, Hawkins, Hilgenkamp, Santiago-Rodríguez, \& Bustamante,_2019).

In contrast, cross-sectional studies consistently demonstrate poorer fundamental movement skills in children with ADHD relative to TD peers; over half of children with ADHD present with impaired motor coordination (Harvey et al., 2009; Kaiser, Schoemaker, Albaret, \& Geuze, 2015). Fundamental movement skills refer to a small number of core "building block" movements that combine to form more complex specialized sequences required to participate in physically active games and activities. Longitudinal studies indicate that mastery of fundamental movement skills during earlier life stages predicts PA in later stages (Lubans, Morgan, Cliff, Barnett, \& Okely, 2010). An intriguing pair of findings suggests that inattention may keep children with ADHD from engaging in the structured activities that develop these skills. First, fundamental movement skills are inversely related to inattention severity but not hyperactivity severity (Fenollar-Cortés, Gallego-Martínez, \& Fuentes, 2017; Fliers et al., 2008). Second, a systematic review of 45 research articles found that between one-quarter and two-thirds of children with ADHD who take stimulant medications improve their motor coordination to levels of TD peers (Kaiser et al., 2015), potentially because medication use increases attention, and thereby engagement in activities which challenge movement skills.

Studies in middle-late childhood also suggest worse levels of physical fitness among children with ADHD or no difference at all by diagnostic status. A study of 947 children, 11-14 years-old, compared laps completed on the FITNESSGRAM Progressive Aerobic Cardiovascular Endurance Run (PACER) test between children with ADHD and TD peers. The PACER tests aerobic capacity by having children run back and forth (20 meters) continuously at an increasing tempo for each lap. The number of laps completed by each child is their score and places them 
Running title: Physical Activity and ADHD

inside healthy or unhealthy "fitness zones" according to their age and gender. The study found that children with ADHD completed 24 laps on the PACER, 5 fewer than TD peers (Martinson et al., 2018). Smaller studies have yielded equivocal results, but none suggest a physical fitness advantage for children with ADHD. A study of Taiwanese children ( $N=36,7-14$ year-old) found that those with ADHD completed 20 laps on the 20-meter PACER compared to 22 laps among TD peers (Pan et al., 2017). In a trial with African-American children with ADHD and/or Disruptive Behavior Disorders ( $\mathrm{N}=35,6-12$ years-old), half of children were categorized by FitnessGram as "Needs Improvement" while the other half were categorized as "Needs Improvement - Health Risk" (Bustamante et al., 2016). Lastly, in a sample of 70 boys (aged $M=9.7$-years, $S D=1.3$ ), investigators found no differences in physical fitness between children with ADHD on medication, children with ADHD not on medication, and TD peers (Verret, Gardiner, \& Béliveau, 2010).

A third area of research in middle-late childhood relates to participation in structured PA programs. Structured programs (e.g., team sports) may be especially beneficial for ADHD because they challenge EF, reinforce children to follow rules and routines, and display prosocial behaviors (Diamond \& Lee, 2011). A recent cross-sectional study found that children with ADHD participating in organized sports evidenced fewer ADHD symptoms than children with ADHD who did not participate in sport (Watson, Timperio, Brown, Hinkley, \& Hesketh, 2019). Unfortunately, the same features that make these programs cognitively beneficial may also make them less enjoyable for children with ADHD. A pair of qualitative studies reveal that children with ADHD (812 years-old) report less enjoyment and participation in structured PA programs, more negative feelings towards structured PA, and a preference for playing with friends (Harvey et al., 2009; Shimoni, Engel-Yeger, \& Tirosh, 2010). In a study of after-school participation among AfricanAmerican elementary school students $(\mathrm{N}=175)$ with ADHD or other Disruptive Behavior Disorders, half of parents (54\%) reported child participation in supervised after-school programming $\geq 2$ days/week; however, sedentary program participation (e.g., tutoring, religious classes) exceeded PA program participation (e.g., park, YMCA) by $83 \%$, and sport participation was exceedingly low as only $10 \%$ of children participated in sports $\geq 2$ days/week (Bustamante, Frazier, Mehta, \& Cua, 2018). In comparison, $25-29 \%$ of children nationally participate in competitive sports regularly (State of Play 2017: Trends and Developments, 2017). This raises concerns about whether children with ADHD are disproportionately pushed out of PA as it becomes increasingly structured, demanding, and selective with age. Additional studies with nationally representative datasets will be important for testing this hypothesis.

STUDIES IN ADOLESCENCE (AGES 13-19)

By adolescence, any earlier PA advantages associated with ADHD and sedentary time appear to have dissolved or reversed. An analysis of NHANES data (2001-2004), found no differences in PA between 12-15 years-old children with ADHD $(\mathrm{N}=199)$ and TD peers $(\mathrm{N}=1,490)$ (Curtin, 2015). In contrast, a large study of 45,897 children and adolescents aged 10-17 year-olds in the US found that ADHD youth not taking medication were $76 \%$ less likely to report meeting PA guidelines and $120 \%$ more likely to exceed sedentary guidelines than TD peers (Cook, Li, \& Heinrich, 2015). Finally, a prospective cohort study of 2,868 live-births in Australia found that 14-year-olds with ADHD were $53 \%$ less likely than TD peers to exercise $2-6$ times per week and $67 \%$ less likely to exercise 7+ times per week (Howard et al., 2011).

\section{Evidence of Transient NeURocognitive EfFEcts of ACUTE Bouts of PA FOR ChILDREN WITH ADHD}

The first test of the impact of acute bouts of exercise on cognitive performance among children with ADHD was published in 1983, shortly after the disorder was named ADD by the American 
Running title: Physical Activity and ADHD

Psychological Association in 1980. Researchers hypothesized that cognitive performance would be optimized by moderate arousal, in accordance with the presence of sufficient but not excessive extra-cellular dopamine levels (the inverted-U hypothesis). They expected that the duration necessary to optimize arousal may be different between children with ADHD $(\mathrm{N}=31)$ and TD peers $(\mathrm{N}=31)$ (Craft, 1983). Children were tested over 4 visits on separate days, cycled for either 0,1 , 5 , or 10-minutes (order randomly counterbalanced) at a target heart rate of $\sim 170 \mathrm{bpm}$, and completed tests of working memory immediately after cycling each day. There were no differences in working memory by exercise duration or even between days exercised and not exercised.

Twenty years later, two within-subjects design studies tested effects of acute bouts of exercise on neurotransmitter function in children with ADHD. The first took proxy measures of dopamine concentration in children with ADHD $(\mathrm{N}=18)$ before and after brief bouts of moderate treadmill walking, vigorous treadmill walking, or quiet rest (Tantillo, Kesick, Hynd, \& Dishman, 2002). Activity (moderate exercise vs. vigorous exercise vs. quiet rest) by time (baseline vs. postintervention), analyses were null. However, in post-hoc subgroup analyses, boys with ADHD had higher dopamine levels following maximal exercise and girls with ADHD had higher dopamine following moderate exercise. In the second study, investigators tested the effects of 20-minutes of vigorous cycling on peripheral neurotransmitter levels in children with ADHD $(N=10)$ and TD peers $(\mathrm{N}=8)$ (Wigal et al., 2003). Children cycled at moderate-vigorous intensity-the highest rate achieved was 178 beats per minute (bpm) among children with ADHD and 189-bpm among TD peers - for 10 consecutive 2-minute bouts interspersed with 1-minute rest. Blood samples were taken prior to, during the last 2 minutes of exercise, 30-minutes following, and 60-minutes following a maximal exercise bout. For both groups, neurotransmitters spiked during intense exercise and returned to baseline levels 30-minutes after exercise. There was a significantly smaller neurotransmitter response during exercise for children with ADHD relative to TD peers but this is difficult to disentangle from the observed difference in maximum heart rate. Findings raised questions about whether children with ADHD might derive greater benefit from exercise due to lower baseline levels of arousal, smaller benefit due to a smaller neurotransmitter response, or simply no difference in response.

Further studies focused on brain function and performance during neuropsychological tasks-a shift in focus from mechanisms to outcomes. These studies can be categorized as investigations of: (1) impact of diagnostic status (ADHD vs. TD) on exercise response, (2) impact of exercise vs. sedentary activities on children with ADHD only, and (3) differential impact of activity by diagnostic status.

In the first category, 2 studies tested the 2-way interaction of time (baseline vs. post-exercise) and diagnosis (ADHD vs. TD). Neither study revealed a differential response to exercise by diagnostic status on 2-way interaction analyses; however, post-hoc analyses yielded conflicting within-group findings (this is the effect of time only independent of any comparison group). Specifically, Mahon and colleagues $(\underline{2013})$ reported that children with ADHD $(\mathrm{N}=21)$ taking medication performed significantly worse on cognitive tasks following exercise (Mahon et al., 2013), whereas Gapin Labban, Bohall, Wooten, \& Chang (2015) reported significant improvement $(\mathrm{d}=0.82)$ following exercise among college students with ADHD ( $\mathrm{N}=10)$ (Gapin et al 2015). Conflicting findings may reflect differences in design. Gapin used moderate intensity PA (50\%$65 \%$ of heart rate reserve), whereas Mahon utilized a more intense exercise protocol- $90 \%$ of VO2 peak for 20-minutes (peak heart rate of $200 \mathrm{bpm}$ )-and administered cognitive tests immediately following exercise, without the conventional rest period of $\sim 15-30$ minutes for heart rate to return to within $\sim 10 \%$ of resting levels (Pontifex, Saliba, Raine, Picchietti, \& Hillman, 2013). Findings from this pair of studies reinforce the initial inverted-U hypothesis, but regarding intensity 
Running title: Physical Activity and ADHD

rather than duration (Craft, 1983), such that vigorous exercise may impair cognition temporarily, especially without rest.

The second category of studies tested a 2-way interaction of activity (exercise vs. sedentary) and time (baseline vs. post-intervention) in children with ADHD only. Two studies utilized 20-minutes of moderate-intensity treadmill running (heart rates between 150-170 bpm), bookended by 5minute warm-up and cool-down, and revealed significant improvements in cognition following exercise compared to sedentary activities on measures of reaction time and inhibition (Chuang, Tsai, Chang, Huang, \& Hung, 2015; Medina et al., 2010). Additionally, Chuang conducted cognitive testing with an EEG cap that revealed significant alterations in neurological attentional and preparatory processes during the task following exercise (Chuang et al., 2015). A third study randomized 46 children aged 8-12 year-old to a 15-minute bout of exergaming at moderatevigorous intensity (mean heart rate $=148 \mathrm{bpm}$ ) or watched a short documentary film. Children randomized to the exergaming group significantly increased performance speed on neurocognitive tasks of EF relative to controls, but were not significantly more accurate (Benzing, Chang, \& Schmidt, 2018).

A final set of studies tested a 3-way interaction between time (baseline vs. post-intervention), activity (exercise vs. sedentary), and diagnostic status (ADHD vs. TD). None of these studies evidenced differential neurocognitive response between activity types by diagnostic status (no 3way interaction); however, all 3 studies pooled children across diagnostic types and reported significant differences-with moderate-large effect sizes-for the 2-way interaction of time (baseline vs. post-exercise) and activity (exercise vs. sedentary control) on allocation of attentional resources by EEG, response speed, and inhibition during neuropsychological tasks (Ludyga et al., 2017; Piepmeier et al., 2015; Pontifex et al., 2013). Pontifex and colleagues (2013) also reported large effect sizes for the 2-way interaction of time and activity on direct assessments of math $(d=1.25)$ and reading comprehension $(d=1.58)$.

Altogether, this evidence from lab-based experiments suggest that acute aerobic exercise [relative to sedentary activities] improves inhibition, sustained attention, and related neurological processes in children with ADHD for transient periods of time after acute bouts. However, there is no evidence of differential response by diagnostic status. Findings are promising but warrant caution regarding their generalizability outside of the laboratory where control is high (exercise mode, duration, and intensity), environments for neuropsychological tests are without distraction (e.g., soundproof rooms) and well-supervised (researcher offering 1:1 attention and encouragement). The priority on internal validity inherently sacrifices external validity. Children with ADHD are likely to perform to their full potential on neuropsychological tasks under these quiet controlled conditions; but classrooms are different, messy and full of distractions-class clowns, bullies, gossip, and romantic interests. In the laboratory, elevated focus from exercise may be applied to performance on EF tasks, but in the classroom there are no guarantees that an increase in focus will be applied to coursework; instead it could be applied to creating the perfect spit ball.

Fortunately, a few studies have investigated effects of PA breaks on classroom behavior. An informative study tested impacts of classroom PA breaks of different durations (i.e., 5-minutes, 10-minutes, and 20-minutes), relative to sedentary breaks, on subsequent classroom behavior of $4^{\text {th }}$ and $5^{\text {th }}$ grade students (Howie, Beets, \& Pate, 2014). The greatest improvements $(10 \%)$ in ontask behavior followed bouts of 10-minutes, with even greater improvement $(30 \%)$ for students who were least on-task initially. These findings support a previous study of 10-minute aerobic PA breaks, which demonstrated a mean improvement of $8 \%$ on-task behavior compared with days without breaks, and 20\% among the least on-task students (Mahar et al., 2006). Specific to ADHD, 
Running title: Physical Activity and ADHD

Ridgway and colleagues used a single-case design to investigate the impact of a 10-minute free play recess at 9:45 am on classroom behavior of three second grade boys with ADHD and three TD peers (Ridgway, Northup, Pellegrin, LaRue, \& Hightsoe, 2003). Systematic observations from 8:30-10:30am on days with and without recess revealed that disruptive behaviors increased linearly over time that children remained in classrooms, especially on days without recess. The effect was so strong that inappropriate behaviors were roughly twice as high at 10:30am as compared to 8:30am. Results indicate that timing may be important to maximize benefits of acute bouts of PA for students with ADHD. These findings, along with evidence suggesting benefits of movement breaks for fitness, cognition, and self-esteem have persuaded researchers and practitioners in the field of education to advocate for the integration of PA throughout the school day, especially among children with ADHD (Lewallen, Hunt, Potts-Datema, Zaza, \& Giles, 2015; Mulrine, Prater, \& Jenkins, 2008). Hence, the acute bout literature provides compelling evidence for the integration of PA into daily routines for children with ADHD to optimize functioning; however, it does not provide insights into whether daily PA alters children's neurodevelopmental trajectories. For this longitudinal studies and multi-week intervention trials are necessary.

\section{EvidenCE Of DuRABle NeUROdEVELOPMENTAL EfFECTS OF LONG-TERM EXERCISE PARTICIPATION FOR CHILDREN WITH ADHD}

Two recent longitudinal twin studies suggest that EF is genetically determined at a rate of 79100\% (Engelhardt, Briley, Mann, Harden, \& Tucker-Drob, 2015; Friedman \& Miyake, 2017; Friedman et al., 2008). This heritability aligns with findings of high heritability of ADHD itself, and provides additional support for the importance of specific genetically-determined neurobiological structures and functions for determining EF and ADHD (Friedman \& Miyake, 2017). For example, white matter integrity is highly heritable (up to $80 \%$ ), but twin studies suggest that, socioeconomic status interacts with heritability of fiber integrity, such that heritability is lowest amongst individuals from low socioeconomic status backgrounds (Chiang et al., 2011); among those with belowaverage IQ, genetics account for only $40 \%$ of fractional anisotropy (FA) variability (Chiang et al., 2011). Importantly, high heritability does not imply that a construct is not modifiable, rather heritability refers to the extent to which genetics explain individual differences with observational designs, while interventions lift the mean across participants. Hence, there is ample room for environmental impact on neurocognitive constructs, especially during development, and a fastgrowing and substantive literature seeks to test the impact of PA on these constructs among children with ADHD.

\section{EVIDENCE FROM OBSERVATIONAL STUDIES}

In a cross-sectional study, Gapin and Etnier (2010) provided accelerometers to 18 boys with ADHD for 7-days, after which they completed neuropsychological tasks. MVPA was related to improved performance on planning but not inhibition or working memory (Gapin \& Etnier, 2010). It is important to note that in cross-sectional studies causality cannot be inferred. In contrast, longitudinal designs test the temporal order of events and, thereby, provide evidence for directionality. In a study of 8,106 Australian children followed from birth, physical inactivity at age 8 predicted inattention severity at age 16 and ADHD symptoms at 8-years predicted both obesity and inactivity at 16 (Khalife et al., 2014). In a study of 232 identical twins in Sweden, youth selfreported PA at 16-17 years-old and their parents reported their ADHD symptoms 3-years later, when the twins were 19-20 years-old. Greater PA during adolescence predicted fewer ADHD symptoms in early adulthood (Rommel et al., 2015), suggesting a durable neurodevelopmental benefit of PA even late in youth development. 
Running title: Physical Activity and ADHD

\section{EVIDENCE FROM MULTI-WEEK PA INTERVENTION STUDIES}

By definition, chronic PA studies are longitudinal-lasting a few weeks to a few months -and thus able to test for changes in stable behaviors most important to parents, educators, and policy makers-including symptoms and impairment. Exemplifying the ambition of this research area is the work of Dr. Jeffrey M. Halperin, developmental neuroscientist at City University of New York. Dr. Halperin developed a PA program for children with ADHD, entitled Training Executive, Attention, and Motor Skills (TEAMS) (Halperin et al., 2013). TEAMS trains parents to engage 3-5 year-old children with ADHD in 30-45 minutes of physically active play each day (Halperin \& Healey, 2011). A core of the program is timing. A PA intervention in early childhood may be more beneficial than an equivalent intervention later in development. This is analogous to throwing a ball through the air, even a small change in angle in the beginning of the flight profoundly alters its final trajectory. Research is ongoing, but results from an open trial suggest improvements in symptom severity at 3-month follow-up (Halperin et al.,2013); sustaining exercise routines for longer periods remains a challenge however (Halperin, 2015).

This area of research has rightfully received disproportionate attention, as the capacity for interventions to alter neurodevelopmental trajectories in ADHD is of paramount interest. To date, over two dozen studies have tested impacts of multi-week PA interventions for children with ADHD, and since 2015, a host of systematic reviews have been published investigating the influence of multi-week interventions on cognitive and behavioral outcomes among children with ADHD [e.g., (Ash, Bowling, Davison, \& Garcia, 2017; Cerrillo-Urbina et al., 2015; Den Heijer et al., 2017; Neudecker, Mewes, Reimers, \& Woll, 2015; Ng, Ho, Chan, Yong, \& Yeo, 2017; Song, Lauseng, Lee, Nordstrom, \& Katch, 2016; Suarez-Manzano, Ruiz-Ariza, De La Torre-Cruz, \& Martinez-Lopez, 2018)]; as well as a few meta-analytic studies [e.g., (Tan, Pooley, \& Speelman, 2016; Vysniauske, Verburgh, Oosterlaan, \& Molendijk, 2016)]. Across reviews, authors have concluded that benefits of moderate-intensity aerobic PA programs are evident in the domains of symptom severity, executive function, and physical health measures. Meta-analyses have estimated small-moderate group $x$ time effect sizes on EF with ranges from Hedges' $g=0.54$ (Vysniauske et al., 2016), $r=.181$ (Tan et al., 2016), and SMD = 0.58 (Cerrillo-Urbina et al., 2015). A meta-analysis of 249 children with ADHD found moderate-large effect sizes on attention $(S M D=0.84)$, hyperactivity/impulsivity $(S M D=0.56)$ (Cerrillo-Urbina et al., 2015). Unfortunately, each meta-analysis combined acute and chronic exercise in analyses, which limits inference. Moreover, multiple systematic reviews have concluded that more rigorous randomized controlled trials are necessary to confirm long-term benefits ( $\mathrm{Ng}$ et al., 2017; Song et al., 2016; SuarezManzano et al., 2018).

Randomized controlled trials are difficult to conduct under any conditions, dozens of decisions create discrepancies across studies that minimize convergence of methods and findings, and execution errors preclude definitive conclusions. Trials of chronic exercise compound these challenges with a host of others: participants cannot be blinded to condition, families move, engagement wanes, large groups of children with ADHD are difficult to manage, adults are too busy to complete measures, and confounders are difficult to control (Hoza, Martin, Pirog, \& Shoulberg, 2016). Common methodological limitations in the chronic PA literature include absence of control groups, non-random assignment to conditions, inadequate power, per protocol analyses, absence of pre-specified primary outcomes, hypotheses, or analyses, misalignment between study analyses and designs, over-alignment of study outcomes with study activities, and failure to meet CONSORT reporting standards.

Despite these limitations, sufficient evidence has been collected to generate some preliminary hypotheses that merit future investigation and can help to inform integration into practice. 
Hypothesis 1: Effects of multi-week intervention studies diminish as outcomes become conceptually more distal from the stimulus.

Figure 1 presents a conceptual model of the impact of chronic PA on brain function, cognition, behavior, and academic performance of children with ADHD. Within-group effect sizes-time effects independent of comparisons-are moderate-large on neuropsychological tasks and parent- and teacher-reported behavioral outcomes. Moreover, engagement with PA programs is associated with greater improvements in benefits derived on these outcomes. For example, a secondary analysis of a 7-week cyber cycling trial for children with ADHD $(\mathrm{N}=103)$ and other behavior disorders found that for every 11-minutes of cyber cycling, children had an associated decline of 11-minutes of time in detention (Bowling et al., 2017). Group $x$ time analyses reinforce these findings, as intervention studies have consistently found significant differences between groups in brain function (Choi, Han, Kang, Jung, \& Renshaw, 2015), neuropsychological tasks of EF (Kang, Choi, Kang, \& Han, 2011), and symptom severity (Hoza et al., 2015). However, we are only aware of one multi-week intervention study that reported academic outcomes and it found small and near-zero effect sizes even within groups (Ramer, Davis, Frazier, Marquez, \& Bustamante, 2018). More research is necessary to test this hypothesis but it stands to reason that with each step taken away from the initial stimulus (PA), as depicted in Figure 1, the signal should get weaker.

Figure 1. Conceptual Model of Chronic PA for ADHD

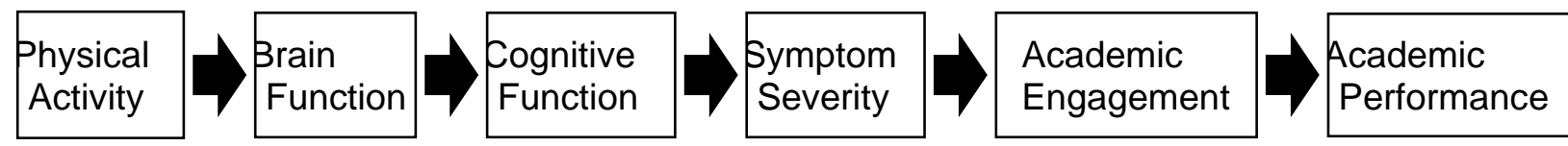

Hypothesis 2: The benefits of multi-week PA interventions are likely to arise disproportionately from features of quality youth programming broadly.

The classic inattention and hyperactivity symptoms that characterize ADHD make children with these disorders challenging to manage in groups. Therefore, engaging them in PA requires proactive engagement and behavior management strategies (e.g., rules, routines, clear expectations and consequences, etc.).These features closely resemble evidence-based psychosocial treatments for ADHD. The only way to disentangle the benefits of these non-PA components of programs from the unique benefits of $P A$ is to provide a comparable but sedentary attention control program. At least three trials of children with ADHD have used this design finding few significant differences between groups despite strong within-group gains in PA conditions (Bustamante et al., 2016; Geladé et al., 2017; Hoza et al., 2015). The latter study, Hoza et al. $(\underline{2015})$, is the largest and amongst the most rigorous studies in the literature, including 94 children with ADHD. Hence, preliminary evidence suggests that when PA groups are compared to active comparison groups, group $x$ time effect sizes on symptom severity are small or near-zero, but when they are compared to no-intervention control groups they are often moderate-large. This hypothesis is also supported by the broad array of PA program formats demonstrating promise, traditional physical education games (Bustamante et al., 2016), distance running (Wendt, 2000), video games (Benzing \& Schmidt, 2017), table tennis (Pan et al., 2016), mechanical horseback riding (Pan et al., 2017), swimming (Verret, Guay, Berthiaume, Gardiner, \& Béliveau, 2012), sports therapy (Choi et al., 2015), yoga (Chou \& Huang, 2017), and interactive cycling (Bowling et al., 2017), among others. If it is the case that the features of PA programs that are most important to improving behavior of children with ADHD are those associated with the environments in which the PA is taking place, this may reasonably be interpreted as a rationale for intentionally tailoring these factors to optimize impact. 
Hypothesis 3: Neurocognitive and behavioral benefits are proportional to the level of engagement with specific cognitive challenges embedded within activities.

Studies of computerized cognitive training show that individuals only improve on the specific task on which they are trained, but these improvements do not generalize to other tasks or settings (Diamond \& Lee, 2011). On this point, compelling arguments have been made that PA that challenges cognition will generate greater cognitive gains than those that do not (Diamond \& Lee, 2011). By this logic, it would be hypothesized that martial arts that directly challenge children's focus would generate greater improvements in focus than games that do not. While most researchers have not identified this training specificity hypothesis explicitly, many augment their PA programs with cognitive challenges. For example, a table tennis program asked children to hit balls of some colors back but not others, an inhibition challenge (Pan et al., 2016). Similar cognitive challenges may be embedded within sedentary activities (e.g., chess, dominoes). On this point, it is possible that children will derive greatest benefit from the activities they find most engaging. If a child is immersed and passionate about chess, and invests focus and energy into it, this may yield greater benefits than cognitively challenging physical activities with which the child does not engage- and vice versa.

\section{Future DiRECTIONS AND POTENTIAL REAL-WORLD APPLICATIONS}

The literature on PA and ADHD is substantive and growing quickly. In rigor and size, it does not approach literatures investigating conventional psychopharmacological or psychosocial treatments. However, cross-sectional studies suggest children with ADHD evidence similar or better PA and ST levels than TD peers during childhood-a period when most PA is free playbut any advantages dissipate by adolescence-a period when PA programs are more structured and selective. Longitudinal studies suggest that PA at earlier life stages predicts symptom severity in subsequent stages. Evidence does not definitively demonstrate PA as an efficacious treatment for ADHD (monotherapy or adjunct therapy); yet, it does seem to complement medication in both acute and chronic studies. The acute bout literature suggests a role for PA in daily routines, though little is known outside of the laboratory about effects of acute bouts of PA on classroom behavior of children with ADHD. In the chronic literature, there is a need for rigorous randomized controlled trials that are attentive to developmental stage, coordinate with existing mental health supports, and conduct long-term follow-up. This has potential to optimize integration of PA into coordinated mental health promotion efforts and maximize neurodevelopmental benefits.

With regard to potential real-world applications, researchers do not yet understand how best to support families of children with ADHD to adopt and sustain daily PA routines. Almost all of the studies reviewed here relied on university resources to motivate children to exercise under controlled settings that are not scalable for larger populations. Community-engaged intervention and services research with a focus on external validity and capacity for dissemination will be critical to achieving these ends. Preliminarily, the pattern of evidence reviewed suggests youth with ADHD may benefit most from PA interventions that directly challenge cognition and enhance fundamental movement skills in childhood, empower youth to participate in structured programs and meet PA guidelines in adolescence, and strategically time PA bouts to maximize focus during difficult periods of daily routines. 
Running title: Physical Activity and ADHD

\section{References:}

Arruda, M.A., Querido, C.N., Bigal, M.E., \& Polanczyk, G.V. (2015). ADHD and mental health status in Brazilian school-age children. Journal of attention disorders, 19(1), 11-17. DOI: https://doi.org/10.1177/1087054712446811

Ash, T., Bowling, A., Davison, K., \& Garcia, J. (2017). Physical activity interventions for children with social, emotional, and behavioral disabilities-a systematic review. Journal of Developmental \& Behavioral Pediatrics, 38(6), 431-445. DOI: https://doi.org/10.1097/dbp.0000000000000452

Barry, R.J., Clarke, A.R., Johnstone, S.J., Mccarthy, R., \& Selikowitz, M. (2009). Electroencephalogram $\theta / \beta$ ratio and arousal in attention-deficit/hyperactivity disorder: Evidence of independent processes. Biological psychiatry, 66(4), 398-401. DOI: https://doi.org/10.1016/i.biopsych.2009.04.027

Benzing, V., Chang, Y.-K., \& Schmidt, M. (2018). Acute physical activity enhances executive functions in children with ADHD. Scientific reports, 8(1), 12382. DOI: https://doi.org/10.1038/s41598-018-30067-8

Benzing, V., \& Schmidt, M. (2017). Cognitively and physically demanding exergaming to improve executive functions of children with attention deficit hyperactivity disorder: a randomised clinical trial. BMC pediatrics, 17(1), 8. DOI: https://doi.org/10.1186/s12887016-0757-9

Bird, H.R., Davies, M., Duarte, C.S., Shen, S., Loeber, R., \& Canino, G.J. (2006). A study of disruptive behavior disorders in Puerto Rican youth: II. Baseline prevalence, comorbidity, and correlates in two sites. Journal of the American Academy of Child \& Adolescent Psychiatry, 45(9), 1042-1053. DOI: https://doi.org/10.1097/01.chi.0000227879.65651.cf

Bowling, A., Slavet, J., Miller, D.P., Haneuse, S., Beardslee, W., \& Davison, K. (2017).

Cybercycling Effects on Classroom Behavior in Children With Behavioral Health Disorders: An RCT. Pediatrics, 139(2), e20161985. DOI: https://doi.org/10.1542/peds.2016-1985

Bustamante, E.E., Davis, C.L., Frazier, S.L., Rusch, D., Fogg, L.F., Atkins, M.S., \& Marquez, D.X. (2016). Randomized controlled trial of exercise for ADHD and disruptive behavior disorders. Medicine and science in sports and exercise, 48(7), 1397. DOI: https://doi.org/10.1249/mss.0000000000000891

Bustamante, E., Frazier, S., Mehta, T., \& Cua, G. (2018). North American Society for Pediatric Exercise Medicine (NASPEM) 2018 Conference Abstracts. Pediatric Exercise Science, 30(4 Suppl 1), S1-S34. DOI: https://journals.humankinetics.com/doi/pdf/10.1123/pes.2018-S1

Caspersen, C.J., Powell, K.E., \& Christenson, G.M. (1985). Physical activity, exercise, and physical fitness: definitions and distinctions for health-related research. Public health reports, 100(2), 126. Retrieved from https://www.ncbi.nlm.nih.gov/pmc/articles/PMC1424733/

Castaneda, R.L.A., Kumar, S., Voigt, R.G., Leibson, C.L., Barbaresi, W.J., Weaver, A.L., . . Katusic, S.K. (2016). Childhood attention-deficit/hyperactivity disorder, sex, and obesity: a longitudinal population-based study. Paper presented at the Mayo Clinic Proceedings. DOI: https://doi.org/10.1016/j.mayocp.2015.09.017

Cerrillo-Urbina, A., García-Hermoso, A., Sánchez-López, M., Pardo-Guijarro, M., Santos Gómez, J., \& Martínez-Vizcaíno, V. (2015). The effects of physical exercise in children with attention deficit hyperactivity disorder: A systematic review and meta-analysis of randomized control trials. Child: care, health and development, 41(6), 779-788. DOI: https://doi.org/10.1111/cch.12255

Chiang, M.C., Mcmahon, K.L., De Zubicaray, G.I., Martin, N.G., Hickie, I., Toga, A.W., . . Thompson, P.M. (2011). Genetics of white matter development: a DTI study of 705 twins 
Running title: Physical Activity and ADHD

and their siblings aged 12 to 29. Neuroimage, 54(3), 2308-2317. DOI:

https://doi.org/10.1016/j.neuroimage.2010.10.015

Choi, J.W., Han, D.H., Kang, K.D., Jung, H.Y., \& Renshaw, P.F. (2015). Aerobic exercise and attention deficit hyperactivity disorder: brain research. Medicine and science in sports and exercise, 47(1), 33. DOl: https://doi.org/10.1249/mss.0000000000000373

Chou, C.-C., \& Huang, C.-J. (2017). Effects of an 8-week yoga program on sustained attention and discrimination function in children with attention deficit hyperactivity disorder. PeerJ, 5, e2883. DOI: https://doi.org/10.7717/peerj.2883

Chuang, L.-Y., Tsai, Y.-J., Chang, Y.-K., Huang, C.-J., \& Hung, T.-M. (2015). Effects of acute aerobic exercise on response preparation in a Go/No Go Task in children with ADHD: an ERP study. Journal of sport and Health science, 4(1), 82-88. DOI: https://doi.org/10.1016/i.jshs.2014.11.002

Cook, B.G., Li, D., \& Heinrich, K.M. (2015). Obesity, physical activity, and sedentary behavior of youth with learning disabilities and ADHD. Journal of learning disabilities, 48(6), 563576. DOI: https://doi.org/10.1177/0022219413518582

Cortese, S., Kelly, C., Chabernaud, C., Proal, E., Di Martino, A., Milham, M.P., \& Castellanos, F.X. (2012). Toward systems neuroscience of ADHD: a meta-analysis of $55 \mathrm{fMRI}$ studies. American Journal of Psychiatry, 169(10), 1038-1055. DOI: https://doi.org/10.1176/appi.ajp.2012.11101521

Cortese, S., Olazagasti, M.a.R., Klein, R.G., Castellanos, F.X., Proal, E., \& Mannuzza, S. (2013). Obesity in men with childhood ADHD: a 33-year controlled, prospective, followup study. Pediatrics, 131(6), e1731-e1738. DOI: https://doi.org/10.1542/peds.2012-0540

Cortese, S., \& Tessari, L. (2017). Attention-Deficit/Hyperactivity Disorder (ADHD) and Obesity: Update 2016. Current psychiatry reports, 19(1). DOI: https://doi.org/10.1007/s11920017-0754-1

Craft, D.H. (1983). Effect of prior exercise on cognitive performance tasks by hyperactive and normal young boys. Perceptual and Motor Skills, 56(3), 979-982. DOI: https://doi.org/10.2466/pms.1983.56.3.979

Curtin, C. (2015). Attention Deficit/Hyperactivity Disorder, Screen Time, Physical Activity, and Diet Quality. (PhD Dissertation), University of Massachusetts Medical School. Retrieved from https://www.researchgate.net/publication/283454646 Attention DeficitHyperactivity Dis order Screen Time Physical Activity and Diet Quality A Dissertation

Davey, C. P. (1973) Physical Exertion and Mental Performance, Ergonomics, 16:5, 595599, DOI: $10.1080 / 00140137308924550$

Davis, C.L., Tomporowski, P.D., Mcdowell, J.E., Austin, B.P., Miller, P.H., Yanasak, N.E., . . Naglieri, J.A. (2011). Exercise improves executive function and achievement and alters brain activation in overweight children: a randomized, controlled trial. Health Psychology, 30(1), 91. https://doi.org/10.1037/a0021766

Den Heijer, A.E., Groen, Y., Tucha, L., Fuermaier, A.B., Koerts, J., Lange, K.W., . . Tucha, O. (2017). Sweat it out? The effects of physical exercise on cognition and behavior in children and adults with ADHD: a systematic literature review. Journal of Neural Transmission, 124(1), 3-26. DOI: https://doi.org/10.1007/s00702-016-1593-7

Diamond, A. (2007). Consequences of variations in genes that affect dopamine in prefrontal cortex. Cerebral cortex, 17(suppl_1), i161-i170. DOI: https://doi.org/10.1093/cercor/bhm082

Diamond, A., \& Lee, K. (2011). Interventions shown to aid executive function development in children 4 to 12 years old. Science, 333(6045), 959-964. DOI:

https://doi.org/10.1126/science.1204529

Ebenegger, V., Marques-Vidal, P.-M., Munsch, S., Quartier, V., Nydegger, A., Barral, J., .. . Puder, J.J. (2012). Relationship of hyperactivity/inattention with adiposity and lifestyle 
Running title: Physical Activity and ADHD

characteristics in preschool children. Journal of child neurology, 27(7), 852-858. DOI: https://doi.org/10.1177/0883073811428009

Engelhardt, L.E., Briley, D.A., Mann, F.D., Harden, K.P., \& Tucker-Drob, E.M. (2015). Genes unite executive functions in childhood. Psychological science, 26(8), 1151-1163. DOI: https://doi.org/10.1177/0956797615577209

Fenollar-Cortés, J., Gallego-Martínez, A., \& Fuentes, L.J. (2017). The role of inattention and hyperactivity/impulsivity in the fine motor coordination in children with ADHD. Research in developmental disabilities, 69, 77-84. DOI: https://doi.org/10.1016/j.ridd.2017.08.003

Fliers, E., Rommelse, N., Vermeulen, S., Altink, M., Buschgens, C., Faraone, S., .. . Buitelaar, J. (2008). Motor coordination problems in children and adolescents with ADHD rated by parents and teachers: effects of age and gender. Journal of Neural Transmission, 115(2), 211-220. DOI: https://doi.org/10.1007/s00702-007-0827-0

Friedman, N.P., \& Miyake, A. (2017). Unity and diversity of executive functions: Individual differences as a window on cognitive structure. Cortex, 86, 186-204. DOI: https://doi.org/10.1016/j.cortex.2016.04.023

Friedman, N.P., Miyake, A., Young, S.E., Defries, J.C., Corley, R.P., \& Hewitt, J.K. (2008). Individual differences in executive functions are almost entirely genetic in origin. Journal of Experimental Psychology: General, 137(2), 201. DOI: https://doi.org/10.1037/00963445.137.2.201

Gapin, J., \& Etnier, J.L. (2010). The relationship between physical activity and executive function performance in children with attention-deficit hyperactivity disorder. Journal of Sport and Exercise Psychology, 32(6), 753-763. DOI: https://doi.org/10.1123/isep.32.6.753

Gapin, J.I., Labban, J.D., Bohall, S.C., Wooten, J.S., \& Chang, Y.-K. (2015). Acute exercise is associated with specific executive functions in college students with ADHD: A preliminary study. Journal of sport and Health science, 4(1), 89-96. DOI: https://doi.org/10.1016/j.jshs.2014.11.003

Geladé, K., Bink, M., Janssen, T.W., Van Mourik, R., Maras, A., \& Oosterlaan, J. (2017). An RCT into the effects of neurofeedback on neurocognitive functioning compared to stimulant medication and physical activity in children with ADHD. European child \& adolescent psychiatry, 26(4), 457-468. DOI: https://doi.org/10.1007/s00787-016-0902-x

Golubović, Š., Milutinović, D., \& Golubović, B. (2014). Benefits of physical exercises in developing certain fitness levels in children with hyperactivity. Journal of psychiatric and mental health nursing, 21(7), 594-600. DOI: https://doi.org/10.1111/jpm.12091

Halperin, J.M. (2015). Body and Mind: Exercise and Play in Young Children with ADHD. Paper presented at the CHADD Annual International Conference on ADHD, New Orleans, LA.

Halperin, J.M., Berwid, O.G., \& O'neill, S. (2014). Healthy body, healthy mind?: the effectiveness of physical activity to treat ADHD in children. Child and adolescent psychiatric clinics of North America, 23(4), 899-936. DOI: https://doi.org/10.1016/i.chc.2014.05.005

Halperin, J.M., \& Healey, D.M. (2011). The influences of environmental enrichment, cognitive enhancement, and physical exercise on brain development: Can we alter the developmental trajectory of ADHD? Neuroscience \& Biobehavioral Reviews, 35(3), 621 634. DOI: https://doi.org/10.1016/j.neubiorev.2010.07.006

Halperin, J.M., Marks, D.J., Bedard, A.-C.V., Chacko, A., Curchack, J.T., Yoon, C.A., \& Healey, D.M. (2013). Training executive, attention, and motor skills: a proof-of-concept study in preschool children with ADHD. Journal of attention disorders, 17(8), 711-721. DOI: https://doi.org/10.1177/1087054711435681

Harvey, W.J., Reid, G., Bloom, G.A., Staples, K., Grizenko, N., Mbekou, V., . . Joober, R. (2009). Physical activity experiences of boys with and without ADHD. Adapted Physical Activity Quarterly, 26(2), 131-150. DOI: https://doi.org/10.1123/apaq.26.2.131 
Running title: Physical Activity and ADHD

Hillman, C.H., Pontifex, M.B., Castelli, D.M., Khan, N.A., Raine, L.B., Scudder, M.R., . . . Kamijo, K. (2014). Effects of the FITKids randomized controlled trial on executive control and brain function. Pediatrics, 134(4), e1063-e1071. DOI:

https://doi.org/10.1542/peds.2013-3219

Howard, A.L., Robinson, M., Smith, G.J., Ambrosini, G.L., Piek, J.P., \& Oddy, W.H. (2011). ADHD is associated with a "Western" dietary pattern in adolescents. Journal of attention disorders, 15(5), 403-411. DOI: https://doi.org/10.1177/1087054710365990

Howie, E.K., Beets, M.W., \& Pate, R.R. (2014). Acute classroom exercise breaks improve ontask behavior in 4th and 5th grade students: a dose-response. Mental Health and Physical Activity, 7(2), 65-71. DOI: https://doi.org/10.1016/j.mhpa.2014.05.002

Hoza, B., Martin, C.P., Pirog, A., \& Shoulberg, E.K. (2016). Using physical activity to manage ADHD symptoms: the state of the evidence. Current psychiatry reports, 18(12), 113. DOI: https://doi.org/10.1007/s11920-016-0749-3

Hoza, B., Smith, A.L., Shoulberg, E.K., Linnea, K.S., Dorsch, T.E., Blazo, J.A., . . Mccabe, G.P. (2015). A randomized trial examining the effects of aerobic physical activity on attention-deficit/hyperactivity disorder symptoms in young children. Journal of abnormal child psychology, 43(4), 655-667. DOI: https://doi.org/10.1007/s10802-014-9929-y

Jensen, P.S., Hinshaw, S.P., Swanson, J.M., Greenhill, L.L., Conners, C.K., Arnold, L.E., . . . Hoza, B. (2001). Findings from the NIMH Multimodal Treatment Study of ADHD (MTA): implications and applications for primary care providers. Journal of Developmental \& Behavioral Pediatrics, 22(1), 60-73. DOI: https://doi.org/10.1097/00004703-20010200000008

Jeong, S.H., Choi, K.-S., Lee, K.Y., Kim, E.-J., Kim, Y.-S., \& Joo, E.-J. (2015). Association between the dopamine transporter gene (DAT1) and attention deficit hyperactivity disorder-related traits in healthy adults. Psychiatric genetics, 25(3), 119-126. DOI: https://doi.org/10.1097/ypg.0000000000000086

Kaiser, M.-L., Schoemaker, M., Albaret, J.-M., \& Geuze, R. (2015). What is the evidence of impaired motor skills and motor control among children with attention deficit hyperactivity disorder (ADHD)? Systematic review of the literature. Research in developmental disabilities, 36, 338-357. DOI: https://doi.org/10.1016/j.ridd.2014.09.023

Kang, K., Choi, J., Kang, S., \& Han, D. (2011). Sports therapy for attention, cognitions and sociality. International journal of sports medicine, 32(12), 953-959. DOI: https://doi.org/10.1055/s-0031-1283175

Khalife, N., Kantomaa, M., Glover, V., Tammelin, T., Laitinen, J., Ebeling, H., . . Rodriguez, A. (2014). Childhood attention-deficit/hyperactivity disorder symptoms are risk factors for obesity and physical inactivity in adolescence. Journal of the American Academy of Child \& Adolescent Psychiatry, 53(4), 425-436. DOI: https://doi.org/10.1016/i.jaac.2014.01.009

Lewallen, T.C., Hunt, H., Potts-Datema, W., Zaza, S., \& Giles, W. (2015). The Whole School, Whole Community, Whole Child model: a new approach for improving educational attainment and healthy development for students. Journal of School Health, 85(11), 729 739. DOI: https://doi.org/10.1111/josh.12310

Lin, C.-Y., Yang, A.-L., \& Su, C.-T. (2013). Objective measurement of weekly physical activity and sensory modulation problems in children with attention deficit hyperactivity disorder. Research in developmental disabilities, 34(10), 3477-3486. DOI: https://doi.org/10.1016/i.ridd.2013.07.021

Lubans, D.R., Morgan, P.J., Cliff, D.P., Barnett, L.M., \& Okely, A.D. (2010). Fundamental movement skills in children and adolescents. Sports medicine, 40(12), 1019-1035. DOI: https://doi.org/10.2165/11536850-000000000-00000

Ludyga, S., Brand, S., Gerber, M., Weber, P., Brotzmann, M., Habibifar, F., \& Pühse, U. (2017). An event-related potential investigation of the acute effects of aerobic and coordinative 
Running title: Physical Activity and ADHD

exercise on inhibitory control in children with ADHD. Developmental cognitive neuroscience, 28, 21-28. DOI: https://doi.org/10.1016/j.dcn.2017.10.007

Mahar, M.T., Murphy, S.K., Rowe, D.A., Golden, J., Shields, A.T., \& Raedeke, T.D. (2006). Effects of a classroom-based program on physical activity and on-task behavior. Medicine and science in sports and exercise, 38(12), 2086. DOI: https://doi.org/10.1249/01.mss.0000235359.16685.a3

Mahon, A.D., Dean, R.S., Mcintosh, D.E., Marjerrison, A.D., Cole, A.S., Woodruff, M.E., \& Lee, M.P. (2013). Acute exercise effects on measures of attention and impulsivity in children with attention deficit/hyperactivity disorder. Journal of Educational and Developmental Psychology, 3(2), 65. DOI: https://doi.org/10.5539/jedp.v3n2p65

Martinson, T., Butterfield, S.A., Mason, C.A., Tu, S., Lehnhard, R.A., \& Nightingale, C.J. (2018). PACER Performance of Children Aged 11-14 With Attention-Deficit Hyperactive Disorder. Pediatric exercise science, 30(2), 237-242. DOI: https://doi.org/10.1123/pes.2017-0048

Mcneill, J., Howard, S.J., Vella, S.A., Santos, R., \& Cliff, D.P. (2018). Physical activity and modified organized sport among preschool children: Associations with cognitive and psychosocial health. Mental Health and Physical Activity, 15, 45-52. DOI: https://doi.org/10.1016/j.mhpa.2018.07.001

Medina, J.A., Netto, T.L., Muszkat, M., Medina, A.C., Botter, D., Orbetelli, R., . . Miranda, M.C. (2010). Exercise impact on sustained attention of ADHD children, methylphenidate effects. ADHD Attention Deficit and Hyperactivity Disorders, 2(1), 49-58. DOI: https://doi.org/10.1007/s12402-009-0018-y

Montiel, C., Peña, J.A., Montiel-Barbero, I., \& Polanczyk, G. (2008). Prevalence rates of attention deficit/hyperactivity disorder in a school sample of Venezuelan children. Child psychiatry and human development, 39(3), 311-322. DOI: https://doi.org/10.1007/s10578-007-0090-5

Mulrine, C.F., Prater, M.A., \& Jenkins, A. (2008). The active classroom: Supporting students with attention deficit hyperactivity disorder through exercise. Teaching exceptional children, 40(5), 16-22. DOI: https://doi.org/10.1177/004005990804000502

Neudecker, C., Mewes, N., Reimers, A.K., \& Woll, A. (2015). Exercise interventions in children and adolescents with ADHD: a systematic review. Journal of attention disorders, 1087054715584053. DOI: https://doi.org/10.1177/1087054715584053

Ng, Q.X., Ho, C.Y.X., Chan, H.W., Yong, B.Z.J., \& Yeo, W.-S. (2017). Managing childhood and adolescent attention-deficit/hyperactivity disorder (ADHD) with exercise: a systematic review. Complementary therapies in medicine, 34, 123-128. DOI: https://doi.org/10.1016/j.ctim.2017.08.018

Ogoh, S., \& Ainslie, P.N. (2009). Regulatory mechanisms of cerebral blood flow during exercise: new concepts. Exercise and sport sciences reviews, 37(3), 123-129. DOI: https://doi.org/10.1097/jes.0b013e3181aa64d7

Pan, C.-Y., Chang, Y.-K., Tsai, C.-L., Chu, C.-H., Cheng, Y.-W., \& Sung, M.-C. (2017). Effects of physical activity intervention on motor proficiency and physical fitness in children with ADHD: An exploratory study. Journal of attention disorders, 21(9), 783-795. DOI: https://doi.org/10.1177/1087054714533192

Pan, C.-Y., Chu, C.-H., Tsai, C.-L., Lo, S.-Y., Cheng, Y.-W., \& Liu, Y.-J. (2016). A racket-sport intervention improves behavioral and cognitive performance in children with attentiondeficit/hyperactivity disorder. Research in developmental disabilities, 57, 1-10. DOI: https://doi.org/10.1016/j.ridd.2016.06.009

Piepmeier, A.T., Shih, C.-H., Whedon, M., Williams, L.M., Davis, M.E., Henning, D.A., . . Etnier, J.L. (2015). The effect of acute exercise on cognitive performance in children with and without ADHD. Journal of sport and Health science, 4(1), 97-104. DOI: https://doi.org/10.1016/i.jshs.2014.11.004 
Running title: Physical Activity and ADHD

Piercy, K.L., Troiano, R.P., Ballard, R.M., Carlson, S.A., Fulton, J.E., Galuska, D.A., . . Olson, R.D. (2018). The physical activity guidelines for Americans. Jama, 320(19), 2020-2028. DOI: https://doi.org/10.1001/jama.2018.14854

Pontifex, M.B., Saliba, B.J., Raine, L.B., Picchietti, D.L., \& Hillman, C.H. (2013). Exercise improves behavioral, neurocognitive, and scholastic performance in children with attention-deficit/hyperactivity disorder. The Journal of pediatrics, 162(3), 543-551. DOI: https://doi.org/10.1016/j.jpeds.2012.08.036

Ramer, J., Hawkins, M., Hilgenkamp, T., Santiago-Rodríguez, M.E., \& Bustamante, E.E. (2019). Objectivey-Measured Physical Activity and Sedentary Time by ADHD Diagnosis: NHANES 2003-2004. Annals of Behavioral Medicine, 53(S1), S369. DOI: https://academic.oup.com/abm/article/53/Supplement 1/S1/5370264

Ramer, J.D., Davis, C.L., Frazier, S.L., Marquez, D.X., \& Bustamante, E.E. (2018). Physical Activity Influence On Behavior Of Children With Adhd \& Dbd During Instruction Using Classroom Observation. Medicine \& Science in Sports \& Exercise, 50(5S), 693. DOI: https://doi.org/10.1249/01.mss.0000538283.55074.7a

Ridgway, A., Northup, J., Pellegrin, A., Larue, R., \& Hightsoe, A. (2003). Effects of recess on the classroom behavior of children with and without attention-deficit hyperactivity disorder. School Psychology Quarterly, 18(3), 253. DOI: https://doi.org/10.1521/scpq.18.3.253.22578

Rommel, A.-S., Lichtenstein, P., Rydell, M., Kuja-Halkola, R., Asherson, P., Kuntsi, J., \& Larsson, H. (2015). Is physical activity causally associated with symptoms of attentiondeficit/hyperactivity disorder? Journal of the American Academy of Child \& Adolescent Psychiatry, 54(7), 565-570. DOI: https://doi.org/10.1016/j.jaac.2015.04.011

Schaeffer, D.J., Krafft, C.E., Schwarz, N.F., Chi, L., Rodrigue, A.L., Pierce, J.E., . . Davis, C.L. (2014). An 8-month exercise intervention alters frontotemporal white matter integrity in overweight children. Psychophysiology, 51(8), 728-733. DOI: https://doi.org/10.1111/psyp.12227

Shimoni, M.A., Engel-Yeger, B., \& Tirosh, E. (2010). Participation in leisure activities among boys with attention deficit hyperactivity disorder. Research in developmental disabilities, 31(6), 1234-1239. DOI: https://doi.org/10.1016/j.ridd.2010.07.022

Song, M., Lauseng, D., Lee, S., Nordstrom, M., \& Katch, V. (2016). Enhanced physical activity improves selected outcomes in children with ADHD: Systematic review. Western journal of nursing research, 38(9), 1155-1184. DOI: https://doi.org/10.1177/0193945916649954

State of Play 2017: Trends and Developments. (2017). Retrieved from https://www.aspeninstitute.org/publications/state-of-play-2017-trends-and-developments/

Suarez-Manzano, S., Ruiz-Ariza, A., De La Torre-Cruz, M., \& Martinez-Lopez, E.J. (2018). Acute and chronic effect of physical activity on cognition and behaviour in young people with ADHD: A systematic review of intervention studies. Research in developmental disabilities, 77, 12-23. DOI: https://doi.org/10.1016/j.ridd.2018.03.015

Swanson, J., Sunohara, G., Kennedy, J., Regino, R., Fineberg, E., Wigal, T., ... Wigal, S. (1998). Association of the dopamine receptor D4 (DRD4) gene with a refined phenotype of attention deficit hyperactivity disorder (ADHD): a family-based approach. Molecular psychiatry, 3(1), 38. DOI: https://doi.org/10.1038/sj.mp.4000354

Tan, B.W., Pooley, J.A., \& Speelman, C.P. (2016). A meta-analytic review of the efficacy of physical exercise interventions on cognition in individuals with autism spectrum disorder and ADHD. Journal of autism and developmental disorders, 46(9), 3126-3143. DOI: https://doi.org/10.1007/s10803-016-2854-x

Tantillo, M., Kesick, C.M., Hynd, G.W., \& Dishman, R.K. (2002). The effects of exercise on children with attention-deficit hyperactivity disorder. Medicine \& Science in Sports \& Exercise. DOI: https://doi.org/10.1097/00005768-200202000-00004 
Running title: Physical Activity and ADHD

Verburgh, L., Königs, M., Scherder, E.J., \& Oosterlaan, J. (2014). Physical exercise and executive functions in preadolescent children, adolescents and young adults: a metaanalysis. Br J Sports Med, 48(12), 973-979. DOI: https://doi.org/10.1136/bjsports-2012091441

Verret, C., Gardiner, P., \& Béliveau, L. (2010). Fitness level and gross motor performance of children with attention-deficit hyperactivity disorder. Adapted Physical Activity Quarterly, 27(4), 337-351. DOI: https://doi.org/10.1123/apaq.27.4.337

Verret, C., Guay, M.-C., Berthiaume, C., Gardiner, P., \& Béliveau, L. (2012). A physical activity program improves behavior and cognitive functions in children with ADHD: an exploratory study. Journal of attention disorders, 16(1), 71-80. DOI: https://doi.org/10.1177/1087054710379735

Vicente, B., Saldivia, S., De La Barra, F., Kohn, R., Pihan, R., Valdivia, M., .. . Melipillan, R. (2012). Prevalence of child and adolescent mental disorders in Chile: a community epidemiological study. Journal of child psychology and psychiatry, 53(10), 1026-1035. DOI: https://doi.org/10.1111/j.1469-7610.2012.02566.x

Visser, S.N., Deubler, E.L., Bitsko, R.H., Holbrook, J.R., \& Danielson, M.L. (2016). Demographic differences among a national sample of US youth with behavioral disorders. Clinical pediatrics, 55(14), 1358-1362. DOI: https://doi.org/10.1177/0009922815623229

Volkow, N.D., Wang, G.-J., Fowler, J.S., \& Ding, Y.-S. (2005). Imaging the effects of methylphenidate on brain dopamine: new model on its therapeutic actions for attentiondeficit/hyperactivity disorder. Biological psychiatry, 57(11), 1410-1415. DOI: https://doi.org/10.1016/j.biopsych.2004.11.006

Volkow, N.D., Wang, G.-J., Kollins, S.H., Wigal, T.L., Newcorn, J.H., Telang, F., . . Ma, Y. (2009). Evaluating dopamine reward pathway in ADHD: clinical implications. Jama, 302(10), 1084-1091. DOI: https://doi.org/10.1001/jama.2009.1308

Vysniauske, R., Verburgh, L., Oosterlaan, J., \& Molendijk, M.L. (2016). The effects of physical exercise on functional outcomes in the treatment of ADHD: a meta-analysis. Journal of attention disorders, 1087054715627489 . DOI: https://doi.org/10.1177/1087054715627489

Watson, A., Timperio, A., Brown, H., Hinkley, T., \& Hesketh, K.D. (2019). Associations between organised sport participation and classroom behaviour outcomes among primary schoolaged children. PloS one, 14(1), e0209354. DOI: https://doi.org/10.1371/journal.pone.0209354

Wendt, M.S. (2000). The effect of an activity program designed with intense physical exercise on the behavior of attention deficit hyperactivity disorder (ADHD) children. State University of New York at Buffalo. Retrieved from https://books.google.co.cr/books/about/The Effect of an Activity Program Design.html ?id=xv77NwAACAAJ\&redir esc $=y$

Wigal, S.B., Nemet, D., Swanson, J.M., Regino, R., Trampush, J., Ziegler, M.G., \& Cooper, D.M. (2003). Catecholamine response to exercise in children with attention deficit hyperactivity disorder. Pediatric research, 53(5), 756. DOI: https://doi.org/10.1203/01.pdr.0000061750.71168.23

Willcutt, E.G., Doyle, A.E., Nigg, J.T., Faraone, S.V., \& Pennington, B.F. (2005). Validity of the executive function theory of attention-deficit/hyperactivity disorder: a meta-analytic review. Biological psychiatry, 57(11), 1336-1346. DOI: https://doi.org/10.1016/j.biopsych.2005.02.006 